\title{
Etiological and Clinical Spectrum of Pancytopenia Based on Bone Marrow Examination
}

\author{
Prodip Kumar Biswas ${ }^{1}$, Md. Hafiz Sardar, ${ }^{2}$ Gopal Chandra Saha, ${ }^{3}$ Mohammed Shahadat Hossain ${ }^{4}$ \\ AKM Humayon Kabir, ${ }^{1}$ Mostofa Kamal Chowdhury, ${ }^{5}$ Tushit Paul ${ }^{6}$
}

\begin{abstract}
:
Background: Bone marrow aspiration is assessed for cytology and trephine biopsy provides overall cellularity, detection of focal lesion and infiltration. Bone marrow study plays a crucial role in identifying cause of aplastic anaemia in clinical practice. This study was carried out to see the etiological and clinical spectrum of pancytopenia based on bone marrow examination.

Materials and Methods: This descriptive study was conducted in the Department of Medicine, Dhaka medical college Hospital, Dhaka, Bangladesh over a 2-year period (August 2016 to July 2018). A total 80 cases of pancytopenia were included in the study. Patients were diagnosed by hemoglobin less than $10 \mathrm{gm} /$ $d L$, total leukocyte count less than 4000/Cumm and platelet count less than 150000/cumm.

Results: Maximum number of cases were seen in age group of 16-30 years (31.25\%) and male to female ratio is I.I:I. The commonest presenting complaint was fever in $40 \%(32 / 80)$ of the cases. Pallor was present in all the patients, Splenomegaly was seen in $20 \%$ (16/80) and hepatomegaly in $12.5 \%$ of the cases (10/80). Petechial hemorrhages were present in 5\% (4/80). The commonest cause of pancytopenia was megaloblastic anemia (35\%) and followed by aplastic anemia (32.5\%).

Conclusion: Pancytopenia is a common clinical problem encountered in clinical practice and the major differential diagnostic considerations of pancytopenia are aplastic anemia, megaloblastic anemia and hematological malignancies.
\end{abstract}

Key words: Pancytopenia, Megaloblastic anemia, aplastic anemia, hematological malignancy.

Copyright: (C) 2019 Biswas PK et al. This is an open access article published under the Creative Commons Attribution-NonCommercial-NoDerivatives 4.0 International License, which permits use, distribution and reproduction in any medium, provided the original work is properly cited, is not changed in any way and it is not used for commercial purposes.

Received: 29 August, 2018;

Accepted: 14 December, 2018

\section{Introduction:}

Pancytopenia is a common entity seen in clinical practice. It is a condition where all the three formed blood elements (red blood cells, white blood cells and platelets) are reduced below

1. Associate Professor of Medicine, Dhaka Medical College, Dhaka

2. Professor of Medicine, Dhaka Medical College, Dhaka

3. Assistant Professor, Department of Radiology and Imaging, Institute of Child and Mother Health, Dhaka

4. Assistant Professor of Medicine, OSD, DGHS. Attached to Faridpur Medical College, Faridpur

5. Assistant Professor, Department of Palliative Medicine, Centre for Palliative Care, Bangabandhu Sheikh Mujib Medical University, Dhaka

6. Post graduate trainee, Dept. of Medicine, Dhaka Medical College, Hospital, Dhaka

Corresponding author: Dr. Prodip Kumar Biswas, Associate Professor of Medicine, Dhaka Medical College, Dhaka. Mobile: 01816828895.Email: prodipaurko@gmail.com. the normal reference range. It has numerous causes. The spectrum of disorders primarily or secondarily affecting the bone marrow may manifest with peripheral pancytopenia. ${ }^{1}$

It is a common clinical problem encountered in clinical practice and should be suspected on clinical ground when a patient presents with unexplained anemia, prolonged fever and bleeding tendency. The presenting symptoms are usually attributable to anemia, leucopenia or thrombocytopenia. ${ }^{1}$

Although pancytopenia is a relatively common hematological entity and a serious clinical problem with exhaustive differential diagnosis, there is relatively little discussion on this abnormality in major text books of hematology and internal medicine. ${ }^{2}$

The mechanisms contributing to pancytopenia include, decrease in hematopoietic cell production, marrow replacement by abnormal cells, suppression of marrow growth and differentiation, ineffective hematopoiesis with 
cell death, defective cell formation, antibody mediated sequestration or destruction of cells in a hypertrophied and overactive reticuloendothelial system. ${ }^{3}$

Bone marrow cellularity varies depending upon the cause. Marrow is hypocellular in primary production defect while in case of ineffective erythropoiesis, increased peripheral utilization or destruction of cell and bone marrow with malignant infiltration are associated with hypercellular and normocellular marrow. ${ }^{4}$

Marrow aspiration is assessed for cytology and trephine biopsy provides overall cellularity, detection of focal lesion and infiltration. The severity of pancytopenia and underlying pathology determine the management and prognosis of patients. The aim of present study was to identify diagnostic reliability of bone marrow aspiration and biopsy in various causes of pancytopenia.

\section{Materials and Methods:}

This is a descriptive study conducted in the Department of Medicine, Dhaka medical college Hospital, Dhaka, Bangladesh over a 2-year period (August 2016 to July 2018). The inclusion criteria for pancytopenia were hemoglobin (Hb) less than $10 \mathrm{gm} / \mathrm{dL}$, total leukocyte count (TLC) less than 4000/cumm and platelet count less than 150000/cumm. Cases fulfilling the definition of pancytopenia but lacking marrow representative bone marrow in the marrow aspirate were excluded from the study.

In each case, bone marrow aspiration was performed by the standard technique using Salah needle; from the posterior superior iliac crest under local anesthesia; taking standard aseptic precautions. Trephine biopsy was performed using Jamshidi needle whenever it was necessary. Bone marrow aspiration smears were stained with Wright stain. Special cytochemical stains such as Myeloperoxidase (MPO) and Periodic-acid Schiff(PAS) stains were also used when required.

\section{Results:}

During the study period of two years, 80 cases of pancytopenia fulfilling the inclusion criteria were included in the study. Age ranged from 8 months to 68 years. Maximum number of cases were seen in age group of 16-30 years $(31.25 \%) .42$ cases were male, and 38 cases were female, male to female ratio was 1.1:1 (Table I).

Table I. Age distribution of the patients

\begin{tabular}{lcc}
\hline Age $($ Yrs $)$ & No of cases & $\%$ \\
\hline$<15 \mathrm{yrs}$ & 9 & 11.25 \\
$16-30 \mathrm{yrs}$ & 25 & 31.25 \\
$31-45 \mathrm{yrs}$ & 21 & 26.25 \\
$46-60 \mathrm{yrs}$ & 19 & 23.75 \\
$>60 \mathrm{yrs}$ & 6 & 7.5 \\
\hline Total & 80 & 100 \\
\hline
\end{tabular}

The commonest presenting complaint was fever in $40 \%$ (32/ 80 ) of the cases. Pallor was present in all the patients, Splenomegaly was seen in $20 \%$ (16/80) and hepatomegaly in $12.5 \%$ of the cases $(10 / 80)$. Petechial hemorrhages were present in 5\% (4/80) (Table II).

Hypersegmented neutrophils were seen in 25\% (20/80) and circulating erythroblasts in $7.5 \%$ (6/80) of cases. Peripheral blood film showed features dimorphic anemia in 30\% (24/80) of cases. Reticulocytosis was seen in $15 \%$ (12/80) of the cases (Table III). The commonest cause of pancytopenia was megaloblastic anemia and was seen in 28/80 (35\%), and followed by aplastic anemia $(32.5 \%)$. The other causes of pancytopenia were acute leukemia, round cell tumor, myelodysplastic syndrome and erythroid hyperplasia (Table IV).

Table II: Clinical findings in pancytopenic patients.

\begin{tabular}{|c|c|c|c|c|c|c|c|}
\hline Diagnosis & $\begin{array}{c}\text { Total } \\
\text { number }\end{array}$ & Fever & Splenomegaly & Hepatomegaly & Petechiae & Lymphadenopathy & $\begin{array}{c}\text { Sternal } \\
\text { tenderness }\end{array}$ \\
\hline Megaloblastic anaemia & 28 & 6 & 4 & 2 & - & - & - \\
\hline Aplastic anaemia & 26 & 12 & - & - & 2 & 2 & - \\
\hline Acute leukemia & 06 & 4 & 2 & 4 & - & - & - \\
\hline Hairy cell leukemia & 02 & - & 2 & - & - & - & - \\
\hline Myelodysplastic syndrome & 02 & - & - & - & - & - & - \\
\hline Reactive marrow & 02 & 2 & 2 & - & - & - & - \\
\hline Round cell tumor & 02 & - & - & - & - & - & - \\
\hline Normocellular marrow & 06 & 6 & 4 & 2 & 2 & - & - \\
\hline Erythroid hyperplasia & 02 & - & - & - & - & - & - \\
\hline Undiagnosed & 02 & 2 & 2 & 2 & - & - & - \\
\hline Inconclusive & 02 & - & - & - & - & - & - \\
\hline Total & 80 & 32 & 16 & 10 & 4 & 2 & - \\
\hline
\end{tabular}


Table III. Peripheral blood smear findings.

\begin{tabular}{lcccccccc}
\hline Diagnosis & $\begin{array}{c}\text { Total } \\
\text { No }\end{array}$ & $\begin{array}{c}\text { Aniso- } \\
\text { cytosis }\end{array}$ & $\begin{array}{c}\text { Dimorphic } \\
\text { picture }\end{array}$ & $\begin{array}{c}\text { Circulating } \\
\text { erythro- } \\
\text { blasts }\end{array}$ & $\begin{array}{c}\text { Hyperseg } \\
\text { Neutrophils }\end{array}$ & $\begin{array}{c}\text { Circulating } \\
\text { immature } \\
\text { cells }\end{array}$ & $\begin{array}{c}\text { Relative } \\
\text { lympho- } \\
\text { cytosis }\end{array}$ & $\begin{array}{c}\text { Reticulo- } \\
\text { cytosis }\end{array}$ \\
\hline Megaloblastic anaemia & 28 & 12 & 14 & 4 & 20 & - & - & 6 \\
Aplastic anaemia & 26 & 12 & 4 & - & - & - & 2 & 2 \\
Acute leukemia & 06 & 2 & - & 2 & - & - & - & - \\
Hairy cell leukemia & 02 & - & - & - & - & - & - & - \\
Myelodysplastic syndrome & 02 & 2 & 2 & - & - & - & - & 2 \\
Reactive marrow & 02 & - & 2 & - & - & - & - & - \\
Round cell tumor & 04 & 2 & - & - & - & - & - & - \\
Normocellular marrow & 04 & 2 & - & - & - & - & - & - \\
Erythroid hyperplasia & 02 & 2 & - & - & - & - & - & 2 \\
Undiagnosed & 02 & - & - & - & - & - & - & - \\
\hline Total & 80 & 40 & 24 & 6 & 20 & - & 2 & 12 \\
\hline
\end{tabular}

Table IV. Bone marrow aspiration and biopsy findings in 80 cases of pancytopenia

\begin{tabular}{lcc}
\hline Diagnosis & No. of cases & Percentage \\
\hline Megaloblastic anaemia & 28 & 35 \\
Aplastic anaemia & 26 & 32.5 \\
Acute lymphoblastic leukemia & 02 & 2.5 \\
Acute myeloblastic leukemia & 02 & 2.5 \\
Aleukemic leukemia & 02 & 2.5 \\
Hairy cell leukemia & 02 & 2.5 \\
Myelodysplastic syndrome & 02 & 2.5 \\
Reactive marrow & 02 & 2.5 \\
Round cell tumor & 02 & 2.5 \\
Normocellular marrow & 06 & 5 \\
Erythroid hyperplasia & 02 & 2.5 \\
Undiagnosed & 02 & 2.5 \\
Inconclusive & 02 & 2.5 \\
\hline Total & 80 & 100 \\
\hline
\end{tabular}

\section{Discussion:}

Pancytopenia is not an uncommon hematological problem encountered in clinical practice and should be suspected on clinical grounds when a patient presents with unexplained pallor, prolonged fever, and tendency to bleed. Bone marrow examination is a frequently requested investigation to determine the cause pancytopenia.

In this study, most cases were seen in adults (16-30 years) and only 9 cases were seen in children. Male patients slightly outnumbered the female with male to female ratio 1.1:1 and this was like study of Jha et al (1.3:1). ${ }^{3}$

In present study megaloblastic anemia is the commonest cause of pancytopenia. This constituted $35 \%$ of total cases of pancytopenia. Findings are similar to other studies tilak and khodke et al in which megaloblastic anemia is a common cause of pancytopenia ${ }^{5,6}$ While this findings are sharp contrast with various studies from the world in which aplastic anemia is commonest cause, this may be due to high prevalence of nutritional anemia in Indian subjects leads the increased frequency of megaloblastic anemia ${ }^{5}$ The cause of megaloblastic anemia was not studied in this study and evaluation of serum folate or vitamin B12 was not available in this study.

The second major cause of pancytopenia was aplastic/ hypoplastic anemia in present study $(32.5 \%)$ which was correlated with Tilak et al and khodke et al. ${ }^{5,6}$ In a study by Keisu et al neoplastic disease was the commonest cause of pancytopenia. ${ }^{7}$ Aplastic anemia may be due to environmental factors or exposure to pesticides/drugs/toxic chemicals.

Acute leukemia was found to be third most common in our study constituted $7.5 \%$ of total cases of pancytopenia in present study findings are similar to the study of Aziz et al acute leukemia constituted almost $10 \%$ of cases of pancytopenia and was third most common cause of pancytopenia. ${ }^{8}$ However percentage very low as compared to study of Jha et al in which it constituted $19.59 \%$ of total cases of pancytopenia. ${ }^{3}$

Only two case of myelodysplastic syndrome was diagnosed in our study. It was the second most common cause of 
pancytopenia in studies by International agranulocytosis and aplastic anemia group. ${ }^{9}$ Two cases of erythroid hyperplasia were noted. Erythroid hyperplasia by itself is not the cause of pancytopenia. Relationship of erythroid hyperplasia to pancytopenia is uncertain. A possible hypersplenism needs to be ruled out in addition to different hemolytic anemias in cases of marrow showing erythroid hyperplasia. No splenomegaly was seen in case of erythroid hyperplasia in present study. In cases of erythroid hyperplasia, correlation with clinical parameters and other laboratory parameters are required. Incidence of Kala azar was high as cause of pancytopenia in various studies however we did not get kala azar as cause of pancytopenia. This is due to different geographic distribution. Difference in the frequency of disorders causing pancytopenia has been due to variation in study design, diagnostic criteria, geographic area, duration of observation, genetic differences and varying exposure to cytotoxic/chemical agents.

\section{Conclusions:}

Bone marrow aspiration is an established diagnostic modality in the evaluation of pancytopenia. The major differential diagnostic considerations of pancytopenia are aplastic anemia, megaloblastic anemia and hematological malignancies. Megaloblastic anemia can be prevented by improving the socioeconomic and nutritional status of our population.

\section{Conflict of interest: None.}

\section{References:}

1. Williams WJ, Bentkr E, Erskv AJ. Haematology - third edition, Singapore, McGraw Hill Book Company 1986:16184.

2. Osama I, Baqal HZ, Faiz A, Nisar H: Pattern of pancytopenia in a general medical ward and a proposed diagnostic approach. J Ayush Med Coll Abbottabad 2004;16:3-7.

3. Jha A, Saami G, Adhikari RC, Panta AD, Jha R Bone Marrow Examination in cases of Pancytopenia. JNMA 2008; 47(169):12-7.

4. Pathak R, Jha A, Sayami G. Evaluation of bone marrow in patients with pancytopenia. J Patho Nepal. 2012;2:265-71.

5. Tilak N, Jain R. Pancytopenia - A clinico-haematological analysis of 77 cases. Indian J Pathol Microbiol. 1999; 42(4):399-404.

6. Khodke $\mathrm{K}$, Bone marrow examination in cases of pancytopenia. J Ind acad clini Med. 2001;2.

7. Keisu M, Ost A. Diagnosis in patients with severe pancytopenia suspected of having aplastic anaemia. Eur J Haematol 1990;45:11-4.

8. Aziz T, Liaquat Ali L, Ansari T, Liaquat HB, Shah S, Jamal AJ. Pancytopenia: Megaloblastic anemia is still the commonest cause. Pak J Med Sci. 2010;26:1132-6.

9. International agranulocytosis and aplastic anaemia study. Incidence of aplastic anaemia, the relevance of diagnostic criteria. Blood. 1987;70:1718-21. 